\title{
Fallowing of selected arable fields in a farmland mosaic affects processes on landscape level: a case study of small mammal communities
}

\author{
*Michał Kozakiewicz, **Jacek Radzikowski, *Marek Ostrowski, *Anna Kozakiewicz \\ *Department of Ecology, University of Warsaw \\ Banacha 2, 02-097 Warsaw, Poland \\ e-mail: kozak@biol.uw.edu.pl \\ ** Department of Hydrobiology University of Warsaw \\ Banacha 2, 02-097 Warsaw, Poland
}

\begin{abstract}
In 2008 on six 1-ha plots the structure and species diversity of small mammal community inhabiting a narrow belt of coastal zone of the Łuknajno Lake (Masurian Lake District, North-East of Poland) were studied. The results obtained were compared with the results of similar studies carried out in the same area in 1981, when still intensive agricultural activities were present around the lake (abandoned in 1991 by leaving the agricultural fields fallow). In comparison with 1981, a decrease in the number of species inhabiting the fringe of the lake was discovered, as well as some significant changes in the domination structure of the community. Currently, the dominant forest species - the bank vole Myodes glareolus (Schreber 1780) and the yellow-necked mouse Apodemus flavicollis (Melchior 1834) - replaced the most numerous in 1981 - the striped field mouse Apodemus agrarius (Pallas 1771). Taking into consideration the fact that environmental conditions at the coastal zone have not changed, it was suggested that the changes in the community of small mammals were caused by setting aside arable lands around the lake. The results obtained lead to the conclusion that the range of the ecological effects of local changes in the landscape mosaic may include an area much larger than the one directly affected by these changes. They constitute the basis for a discussion on the relationship between various elements of environmental mosaic in heterogeneous landscape.
\end{abstract}

Key words: small mammals, ecological landscape, abandoned fields, lake coastal zone.

\section{Introduction}

There are many different definitions of ecological landscape in the literature, but the two main characteristics of the landscape are strongly pointed out in all of them. The first is the specific structure of the landscape, where the elements forming it - ecosystems, quasi-ecosystems (e.g. small woodlots), and others (e.g. anthropogenic elements) border with one another but do not penetrate one another in space (Forman \& Godron 1996). Ecological landscape is therefore a kind of mosaic of numerous structural ele- ments of different characteristics, sizes, shapes and spatial arrangements (e.g. Wiens 1995). The second important feature of the ecological landscape is the character of interactions among its structural elements. The kind and intensity of these interactions should depend on the distribution of landscape elements in space, on the type of elements bordering together, and on their size and shape (Banach et al. 1979; Fahrig 2003). The specific interrelations between its structural elements make the ecological landscape an integrated ecological system (e.g. Hilty et al. 2006). 
The interactions between structural elements of the landscape can be realized through a one-way migration or through the use of resources by individuals located in different environmental patches. Such influences do not need to be reduced only to the border zones of the adjacent environmental patches; they may affect entire patches and even patches of environments not bordering directly with each other. It appears that the extent and strength of these interactions should depend, inter alia, on the distance between the environmental patches, as well as on the type of environments that are between them, which can inhibit (barriers) or facilitate (corridors) free movements of individuals (Kozakiewicz 1993; Ims 1995). Understanding the structure of the landscape and the type and strength of interactions between its components should thus enable to describe it in terms of stability and the degree of integration. Thus, it might be expected that effects of disturbing activities carried out by humans in one of the components of the landscape may in fact move to another, and affect the functioning of the whole system.

In Poland, throughout the last two decades, hundreds of thousands of hectares of arable land had been set aside through fallowing as a result of the social, economic and political changes taking place in the 1990s. Agricultural fields are habitats providing excellent food resources for many animal species during most of the vegetative season. Thus, changes in agricultural land use, particularly the abandonment of agricultural fields, may lead to major changes in other landscape elements and, finally - in the functioning of the whole landscapes.

The aim of the study was to evaluate the effect of setting aside of the agricultural land on the functioning of landscape mosaic by comparing small mammal communities inhabiting lake coastal zone surrounded by arable land before and after the fallowing of bordering agricultural fields.

\section{A case study: small mammal communities of Luknajno Lake coastal zone}

\subsection{Study area, methods}

The studies had been carried out in the coastal habitats of the Łuknajno Lake (Masurian Lake District, north-eastern Poland (53⒋ $\left.\mathrm{N}, 21^{\circ} 34^{\prime} \mathrm{E}\right)$ ). The lake is situated in arable land and surrounded by formerly cultivated crop fields, pastures and meadows. Its shore line consists mainly of a narrow (approximately $100 \mathrm{~m}$ ) belt of alder wood or willow shrubs and has no direct connection with forest. The nearest forest complex, at its closest point, is situated about $1 \mathrm{~km}$ away from the lake shore. In 1991 the arable fields surrounding Łuknajno Lake have been fallowed and the processes of secondary succession began.
Small mammals have been trapped twice - first time in 1981 (10 years before fallowing of surrounding crop fields) and for the second time in 2008 (17 years after fallowing). Both times animals were trapped at the same six sites situated in different parts of the lake shore, representing all types of vegetation cover that remained unchanged during the time of the whole study, because of year-to-year changes in lake water levels regulated by humans (Kozakiewicz \& Kozakiewicz 2008). Study plots were square-shaped, each of them approximately 1 ha in size. In each plot traps were arranged in a $15 \times 15 \mathrm{~m}$ grid. Animals were snaptrapped (1981) and life-trapped (2008) in three-day series of trappings four times a year in 1981 (spring - April, summer - July, autumn - September, winter - February) and three times a year in 2008 (spring - April, summer - July, autumn - September).

\subsection{Results}

Overall 656 individuals belonging to 12 small mammal species were caught in 1981 and 788 individuals representing 10 species in 2008 (Table 1). In total catch in the year 1981 the striped field mouse Apodemus agrarius (Pallas 1771) predominated markedly, while two other species - bank vole Myodes glareolus (Schreber 1780) and root vole Microtus oeconomus (Pallas 1776) were co-dominants (Fig. 1). In 2008 the domination structure of small mammal community changed markedly, as compared to 1981: two forest species - bank vole and yellow-necked mouse Apodemus flavicollis (Melchior 1834) predominated, while previously dominating striped field mouse was much less numerous (Fig. 1).

In 2008, there were no individuals caught of the brown rat Rattus norvegicus (Berkenhout 1769), wood mouse Apodemus sylvaticus (Linnaeus 1758) nor the common vole Microtus arvalis (Pallas 1779), and in 1981 on the studied area the northern birch mouse Sicista betulina (Pallas 1778), present in the study from 2008, did not occur. Despite the decrease in the number of species recorded on the bank of the lake after fallowing of the surrounding arable lands, both the Shannon-Wiener coefficient of species diversity and Sheldon's evenness index (Krebs 1989) increased (Table 2). The number of species during each of the different seasons of study also increased (Table 3 ).

Comparing seasonal variability of the structure (species composition and domination) of small mammal communities inhabiting coastal zone of the Łuknajno Lake before and after fallowing of the surrounding arable lands has shown a considerably higher variability in the period before the fields had been set aside. In 1981, the numerically dominant species changed every season - during springtime it was the bank vole, in the summertime - the root vole, and in autumn - striped field mouse. In 2008 (17 years after the fallowing of the fields) the structure of 
1981

2008

SPRING
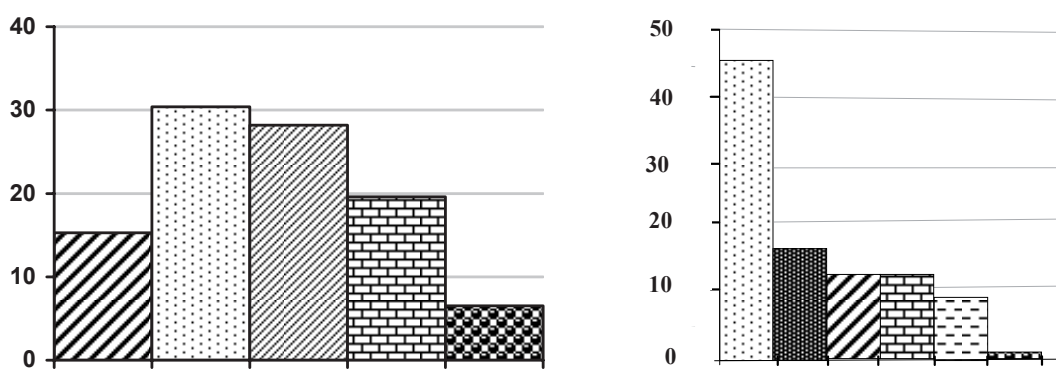

\section{SUMMER}
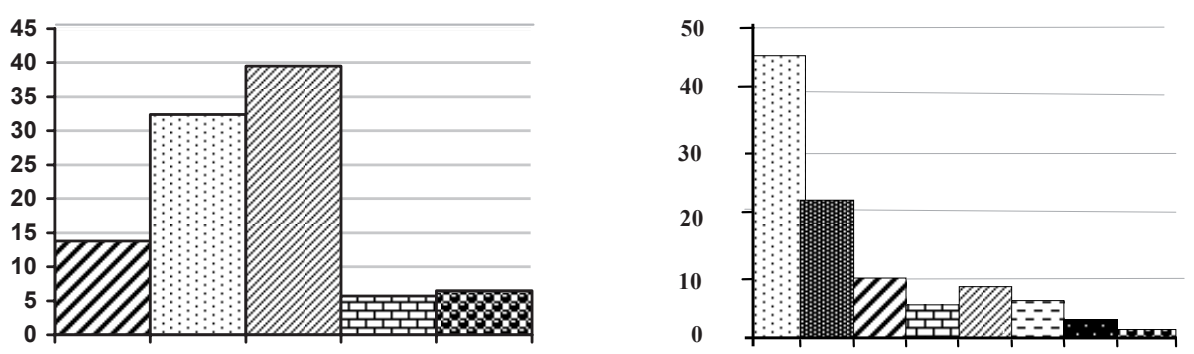

\section{AUTUMN}

$\%$

$\%$
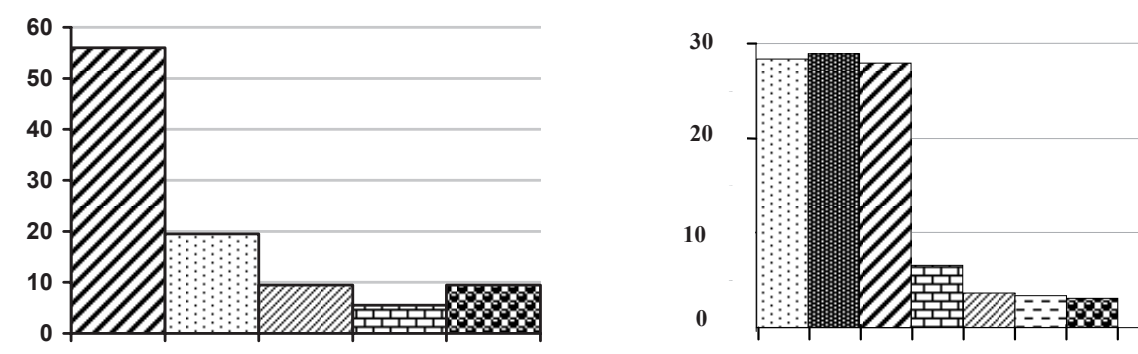

species

species
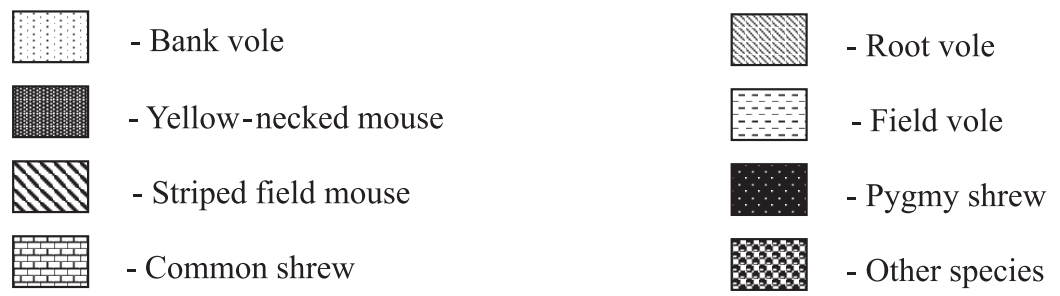

Figure 1. The dominance of species (\%) in the small mammal community inhabiting lake coastal zone for the whole catch in 1981 (A) and 2008 (B) series of trappings. Data for 1981 from Kozakiewicz et al. 1992, modified 
Table 1. Number of animals representing different species in the total catch in the coastal zone of Łuknajno Lake before (1981, data from Kozakiewicz et al. 1992) and after (2008) the fallowing of arable fields

\begin{tabular}{|l|c|c|}
\hline \multicolumn{1}{|c|}{ Species } & 1981 & 2008 \\
\hline Apodemus agrarius & 260 & 145 \\
\hline Myodes glareolus & 160 & 278 \\
\hline Microtus oeconomus & 134 & 46 \\
\hline Sorex araneus & 43 & 59 \\
\hline Sorex minutus & 26 & 14 \\
\hline Apodemus flavicollis & 17 & 63 \\
\hline Neomys fodiens & 5 & 2 \\
\hline Micromys minutus & 4 & - \\
\hline Microtus arvalis & 3 & 44 \\
\hline Microtus agrestis & 2 & - \\
\hline Apodemus sylvaticus & 1 & - \\
\hline Rattus norvegicus & 656 & 198 \\
\hline Sicista betulina & & \\
\hline Total & 1 & - \\
\hline
\end{tabular}

Table 2. Values of Shannon-Wiener $(\mathrm{H})$ and Sheldon evenness (E) coefficients for the total catch in the coastal zone of Łuknajno Lake before (1981, data from Kozakiewicz et al. 1992) and after (2008) the fallowing of arable fields

\begin{tabular}{|c|c|c|}
\hline Index & 1981 & 2008 \\
\hline $\mathrm{H}$ & 2.26 & 2.42 \\
\hline $\mathrm{E}$ & 0.63 & 0.73 \\
\hline
\end{tabular}

Table 3. Seasonal changes in the number of species caught in the Lake Łuknajno coastal zone before (1981, data from Kozakiewicz et al. 1992) and after (2008) the fallowing of arable fields

\begin{tabular}{|c|c|c|c|c|}
\hline Year & Spring & Summer & Autumn & $\begin{array}{c}\text { Number of species } \\
\text { present in all seasons }\end{array}$ \\
\hline 1981 & 4 & 5 & 7 & 4 \\
\hline 2008 & 6 & 9 & 9 & 6 \\
\hline
\end{tabular}

dominance of the species was less variable - both in spring and summertime dominated the bank vole, and in autumn occurred a co-dominance of three species - the bank vole, yellow-necked mouse and striped field mouse (Fig. 2).

\section{Discussion}

Compared to the results from 1981, in 2008 the species composition of small mammal community has not changed significantly - the differences concern only the extremely rare species in a given year of study: brown rat, wood mouse and common vole (present in 1981, absent in 2008) and northern birch mouse (absent in 1981, present in 2008). All of the more numerous species of rodents and insectivores were found in both years of study, but their proportions have changed significantly.

While in 2008 the studied area was dominated by forest species (bank vole and yellow-necked mouse), in 1981 the most numerous was the striped field mouse - species related with agricultural lands, and the second most numerous in 2008, the yellow-necked mouse, constituted only 2.6 per cent of the total catch (Fig. 1). The structure of the small mammal community in 1981 was very similar to the one noted by Puky and Farkas (1998) in a mosaic of agricultural land near Balaton Lake (high number of striped field mouse, and lower numbers of forest species).

Thus the structure of the small mammal community inhabiting coastal areas of the Łuknajno Lake after fallowing of the surrounding arable lands has changed considerably. As mentioned above, the characteristics of vegetation growing on lake banks did not change significantly during this time. Hence, it seems that, similarly like in the case of other landscape elements (forest complexes), bordering fallowed areas (Kozakiewicz \& Kozakiewicz 2008), the cause of the observed changes is the abandonment of agricultural activities in most areas adjacent to the area of research.

About half lower occurrence of the striped field mouse in 2008, and the total absence of the common vole are probably related to the lack of very rich food resources that the seasonal crop production provided to the rodents. On the other hand, a significant increase in the number of the bank vole (about 10 per cent) and the yellow-necked mouse (about 20 per cent) results probably from the possibility of an easier migration of these species from the forest located about $1 \mathrm{~km}$ from the studied area. Fallowing the arable fields and the gradual processes of seedling of the trees on their area was in fact the cause of the abolition of the barrier effect, that open spaces constitute for the forest rodent species (e.g. Kozakiewicz et al. 1999).

Among all changes observed in the studied community of small mammals, the hardest to explain is the fact of a significant decrease in the number of the root vole, ob- 
A

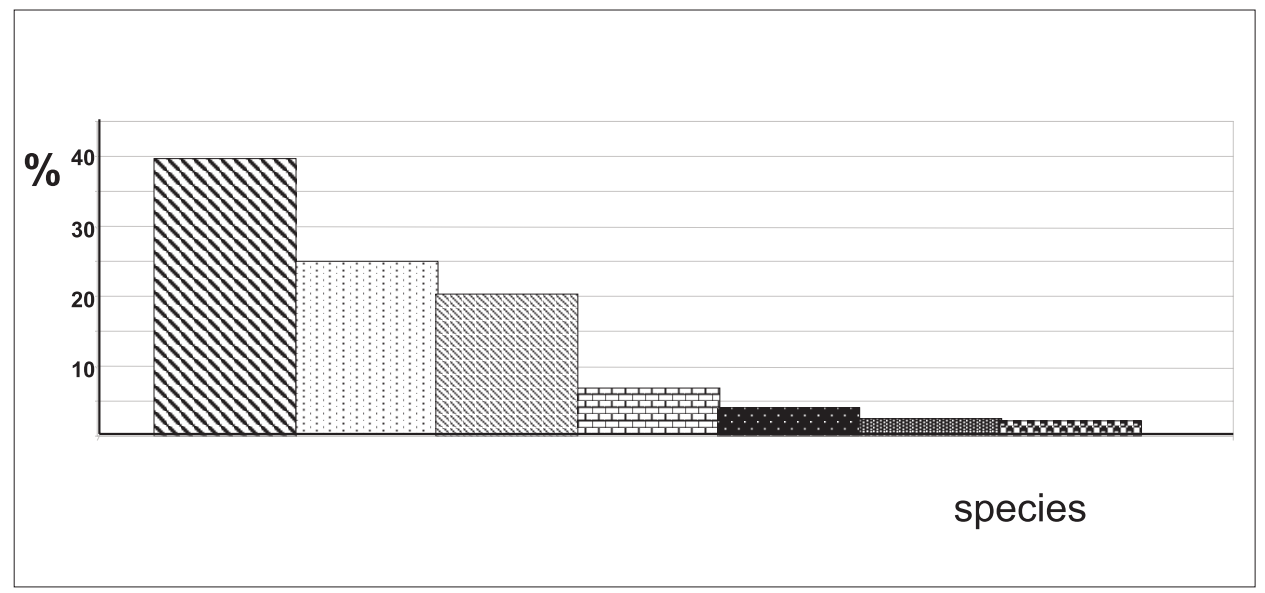

B

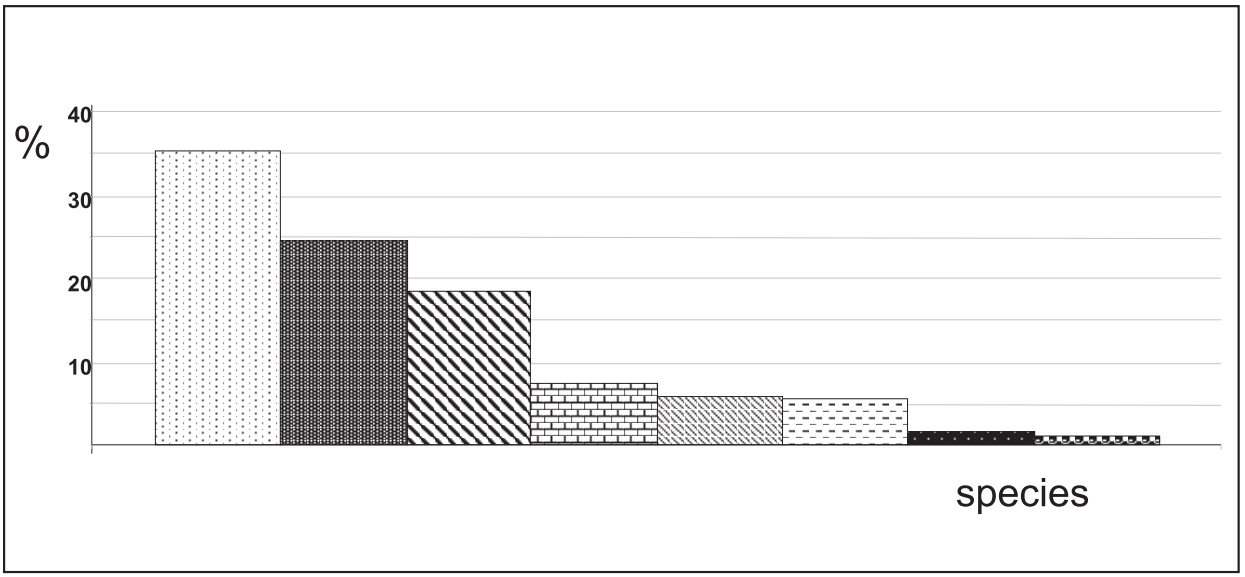

Figure 2. Seasonal changes in the dominance of species (\%) in the small mammal community inhabiting lake coastal zone in 1981 (A) and 2008 (B) series of trappings. Data for 1981 from Kozakiewicz et al. 1992, modified. Species marked as in Figure 1

served in 2008. This species is competitively strong (Hoset \& Steen 2007; Henttonen et al. 1977) but could be displaced from the area around Luknajno Lake by other competitively strong species, which is the yellow-necked mouse (Andrzejewski \& Olszewski 1963; Gliwicz 1981; Kozakiewicz 1987; Kozakiewicz \& Kozakiewicz 2008). Perhaps root vole, driven from the coastal areas by forest species growing in numbers, resettled from these areas to other parts in the vicinity of small water reservoirs created in hollows after obstruction of drainage tubing on the fields that have been set-aside.

The share of insectivorous species in the area surrounding the Łuknajno Lake has not changed significantly within 27 years that separate studies discussed in this paper. Common shrew Sorex araneus (Linnaeus 1758) both in 1981, and in 2008 was the fourth most numerous species of small mammals inhabiting the coastal areas of Luknajno Lake and its share remained at similar level (about 6-7 per cent). Water shrew Neomys fodiens (Pennant 1771) in both years of the study occurred in very small numbers (5-6 indi- viduals throughout the whole area of study), and in 2008 the number and the share of pygmy shrew Sorex minutus (Linnaeus 1766) decreased (from 26 to 14 individuals and from 4 to 1.8 per cent). In this case, the decrease of about 12 individuals, however, may be irrelevant, given that traps used in 2008 are not suitable for harvesting insectivorous species (Pucek 1969; Aulak 1970). During the research in 1981 even 12 species of small mammals were found - for comparison, in 2008 there were only 10 (Table 1).

It is interesting, that species diversity and evenness for the entire year 2008 resulted to be higher than those for 1981 (Table 2). This is a consequence of the fact that in the whole 1981 up to 6 different species occurred in very small numbers, while in 2008 , only three species were represented by a such a small number of individuals.

It should also be noted that in 2008 the dominance structure in the groups of small mammals' inhabiting the studied area was characterized by lower seasonal changes, compared to the groups in the same area but 17 years earlier. All these considerations seem to lead to a conclusion that 
there is a greater stability of the small mammals' grouping inhabiting the coastal zone of the lake after changes (after the agricultural practices ceased) that have occurred in its environment.

These results indicate that the fallowing arable lands around Luknajno Lake brought multiple effects on small mammal community inhabiting its coastal areas: an increase in the share of forest species, a decrease in the number of species associated with crops and an increase in species composition stability.

\section{Final conclusions}

1. Setting-aside arable land has reduced patchiness and seasonal variability of environments in the areas surrounding the lake. Consequently, this has resulted in some significant changes in the structure of the small mammal community inhabiting coastal zone.

2 . The species clearly dominant before the fallowing of fields - the striped field mouse - has given way to the two typical forest rodent species - the bank vole and yellownecked mouse.

3. Community structure and dynamics of abundance of particular species of small mammals inhabiting coastal areas of the Łuknajno Lake are closely related to the dynamics of communities inhabiting surrounding areas.

4. Some human activities disturbing the environment, such as fallowing the fields, conducted in one of the components of the landscape may affect others and influence the functioning of the system, which is an ecological landscape.

5. Any activities that cause changes in natural environment, even those of a local range, must be preceded by an analysis of the ecological effects that may occur on a broader spatial scale - in the entire landscape.

\section{References}

Andrzejewski R. \& Olszewski J., 1963, Social behaviour and iterspecific relations in Apodemus flavicollis (Melchior 1834) and Clethrionomys glareolus (Schreber 1780), Acta Theriologica 7: 155-168.

Aulak W., 1970, Small mammal communities of the Białowieża National Park, Acta Theriologica 15: 465-515.

Banach A., Kozakiewicz A. \& Kozakiewicz M., 1979, Krajobraz ekologiczny jako układ ekosystemów wzajemnie na siebie oddziaływających [Ecological landscape as a structure of interrelated ecosystems], Wiadomości Ekologiczne 25: 41-47.

Fahrig L., 2003, Effects of habitat fragmentation on biodiversity, Annual Review on Ecology and Systematics 34: 487-515.
Forman R. T. T. \& Godron M., 1986, Landscape ecology, John Wiley, New York, Chichester, Brisbane, Toronto, Singapore.

Gliwicz J., 1981, Competitive interactions within a forest rodent community in cetral Poland, Oikos 37: 353-362.

Henttonen H., Kaikusalo A., Tast J. \& Viitala J., 1977, Interspecific competition between small rodents in subarctic and boreal ecosystems, Oikos 29: 581-590.

Hilty J. A., Lidicker Jr. W. Z. \& Merenlender A. M., 2006, Corridor Ecology. The Science and Practice of Linking Landscapes for Biodiversity Conservation, Island Press, Washington, Covelo, London.

Hoset K. S. \& Steen H., 2007, Relaxed competition during winter may explain the coexistence of two sympatric Microtus species, Annales Zoologici Fennici 44: 415-424.

Ims R. A., 1995, Movement patterns related to spatial structures, [in:] L. Hansson, L. Fahrig, G. Merriam (eds.), Mosaic landscapes and ecological processes, Chapman \& Hall, London, Glasgow, Weinheim, New York, Tokyo, Melbourne, Madras: 85-109.

Kozakiewicz A., 1987, Spatial distribution and interspecific interactions in small rodent community of a lake coastal zone, Acta Theriologica 32: 433-447.

Kozakiewicz A., Kozakiewicz M. \& Choszczewska B., 1992, Small mammal communities of the nature reserve „Łuknajno Lake” coastal zone, Parki Narodowe i Rezerwaty Przyrody 11: 121-130.

Kozakiewicz M., 1993, Habitat isolation and ecological barriers - the effect on small mammal populations and communities, Acta Theriologica 38: 1-30.

Kozakiewicz M., Gortat T., Kozakiewicz A. \& Barkowska M., 1999, Effects of habitat fragmentation on four rodent species in a Polish farm landscape, Landscape 14: 391-400.

Kozakiewicz M. \& Kozakiewicz A., 2008, Long-term dynamics and biodiversity changes in small mammal communities in a mosaic of agricultural and forest habitats, Annales Zoologici Fennici 45: 263-269.

Krebs C. J., 1989, Ecological methodology, Harper \& Row, New York.

Pucek Z., 1969, Trap response and estimation of numbers of shrews in removal catches, Acta Theriologica 14: 403-426.

Puky M. \& Farkas J., 1998, Small mammal (Insectivora, Rodentia) and amphibian communities in the drainage area of Lake Balaton, Opuscula Zoologica 31: 89-96.

Wiens J. A., 1995, Landscape mosaics and ecological theory, [in:] L. Hansson, L. Fahrig, G. Merriam (eds.), Mosaic landscapes and ecological processes, Chapman \& Hall, London, Glasgow, Weinheim, New York, Tokyo, Melbourne, Madras: 1-26. 